\title{
Towards the democratisation of design: a generalised capability model for FDM
}

\section{Mark Goudswaard*, Ben Hicks and Aydin Nassehi}

\author{
CAME School of Engineering, \\ The University of Bristol, \\ Queen's Building, University Walk, \\ Bristol, BS8 1TR, UK \\ Email: mark.goudswaard@bristol.ac.uk \\ Email: ben.hicks@bristol.ac.uk \\ Email: aydin.nassehi@bristol.ac.uk \\ *Corresponding author
}

\begin{abstract}
The manufacture of parts via fused deposition modelling (FDM) is inhibited by a lack of understanding of the manufacturing process, resulting in parts having unreliable mechanical properties. Correspondingly, this paper considers the incorporation of capability profiles (CPs) for FDM as a solution. The evolved requirements of CPs for FDM are considered and the necessary process information that would be incorporated within them is presented. A review of existing literature of the effect of process parameters on mechanical properties of FDM parts identifies process variability and the effects of shape and scale as areas insufficiently studied. To address this, tensile tests are conducted revealing: 1) variation $(26 \%)$ in identical test specimens' UTS; 2) that properties do not scale linearly with specimen size; 3 ) that cross-sectional shape directly impacts mechanical performance. These results are used to define the parameters required for a capability profile for FDM and subsequently demonstrate its functionality.
\end{abstract}

Keywords: democratisation of design; material testing; capability profiles; additive manufacturing; design for additive manufacturing; mechanical properties; filament deposition modelling; FDM; manufacturing parameters.

Reference to this paper should be made as follows: Goudswaard, M., Hicks, B. and Nassehi, A. (2020) 'Towards the democratisation of design: a generalised capability model for FDM', Int. J. Agile Systems and Management, Vol. 13, No. 1, pp.79-101.

Biographical notes: Mark Goudswaard is a Research Associate in the Design and Manufacturing futures Laboratory at the University of Bristol. His research areas include digital-physical twinning, transdisciplinary engineering and neuro-cognition in the design process. He completed his PhD at Bristol in 2019 where he investigated how the practice of design can be made more accessible to enable more people to reap the benefits afforded by additive manufacture.

Ben Hicks is the head Head of Engineering Systems and Design, a Codirector of the Design and Manufacturing Futures Lab and the Director of the EPSRC-funded Language of Collaborative Manufacturing Programme Grant, and $£ 1.6 \mathrm{M}$ EPSRC project on digital-physical twinning. His research concerns tools and methods to support the design and improvement of products, machines and manufacturing systems. His research has resulted in the creation 
of new processes and methods for design management, methods for computer-based design and optimisation, approaches for managing manufacturing information and knowledge discovery, and techniques for modelling machine-material interaction.

Aydin Nassehi is a Reader in Manufacturing Systems and a CIRP associate member in the Department of Mechanical Engineering, University of Bristol. $\mathrm{He}$ received his $\mathrm{PhD}$ in Innovative Manufacturing Technology in 2007 and has since studied for an MSc in Software Engineering. He has more than 88 academic publications including more than 20 journal papers and a research portfolio of $£ 2.5$ million. His research interests are in informatics and artificial intelligence in manufacturing.

This paper is a revised and expanded version of a paper entitled 'Towards the democratisation of design: exploration of variability in the process of filament deposition modelling in desktop additive manufacture' presented at the Transdisciplinary Engineering Conference 2018, Modena, 3-6 July 2018.

\section{Introduction}

The democratisation of design is the process of allowing "more non-designers to become to become involved in idea generation, development and production of products, services or processes" (Fleischmann, 2015). Consequently, it has the potential to facilitate the ultimate agile product development process (PDP) with the end user able to innovate and create products for themselves.

In parallel with the inception and evolution of the concept of democratising design, the paradigm shift to low cost additive manufacturing (AM) techniques, such as filament deposition modelling (FDM), has provided a technology platform that can underpin democratisation. FDM offers the potential to de-skill manufacturing without loss of capability (Garrett, 2014) whilst providing significant economic (Wittbrodt et al., 2013) and sustainability benefits (Gebler et al., 2014) in the manufacture of day to day consumer goods. In addition to these advantages, FDM (as well as other AM technologies) offer a wide range of design freedoms that permit the realisation of structures not possible by other traditional manufacturing methods (Attaran, 2017).

Permitting people to design and manufacture for themselves is a step towards more agile product development processes. By moving elements of design and manufacturing from the developer to the end user, companies can innovate and develop products more quickly, enabling a faster response to identified customer needs. Through the use of manufacturing process such as FDM, the PDP is simplified and reduced. This is due to manufacture being off-loaded to the end user which results in greatly reduced lead times as physical supply chains are removed by supplying products instantly via digital means.

A corollary of democratising design and manufacture is that non-technical stakeholder groups must either fully or partially fulfil the roles of the traditional design engineer, structural engineer and manufacturing engineer in order to create a functional artefact. A fundamental aim of democratising design therefore is to provide tools than can support non-technical users to carry out tasks normally undertaken by experts. To achieve this, it is necessary provide the user with support in making reasoned design decisions, which, in the design of structural parts would necessitate a Capability Profile (CP) 
detailing the impact that manufacturing parameters have on the properties of finished parts. Whilst some empirical relationships have been developed for some of these parameters, there is no present method that enables the accurate prediction of part behaviour.

Correspondingly, this paper presents an overall methodology to achieve the democratisation of design with particular attention to the requirements, architecture and population of a capability profile capable of enabling a non-technical user to design and manufacture parts with reliable properties. It represents a new design approach that enables product customisation and improvements in process flexibility.

Whilst the presented methodology can be applied to other AM techniques, this paper focuses on its application to the FDM process. This is because of the previously mentioned sustainability and economic benefits that it affords, and also that it is the most widely used AM technique, accounting for $69 \%$ of printers used in the consumer market (Holst, 2018).

The novelty in the work presented in this paper is twofold. Firstly, experimental testing explores the effect of shape and scale on the mechanical behaviour of FDM parts - two properties not considered in existing work. Secondly, the development and use of an FDM capability profile is novel, and its incorporation within the design for FDM process enables appraisal of the feasibility of such an approach in creating parts with reliable properties.

Figure 1 Methodology diagram showing workflow through paper

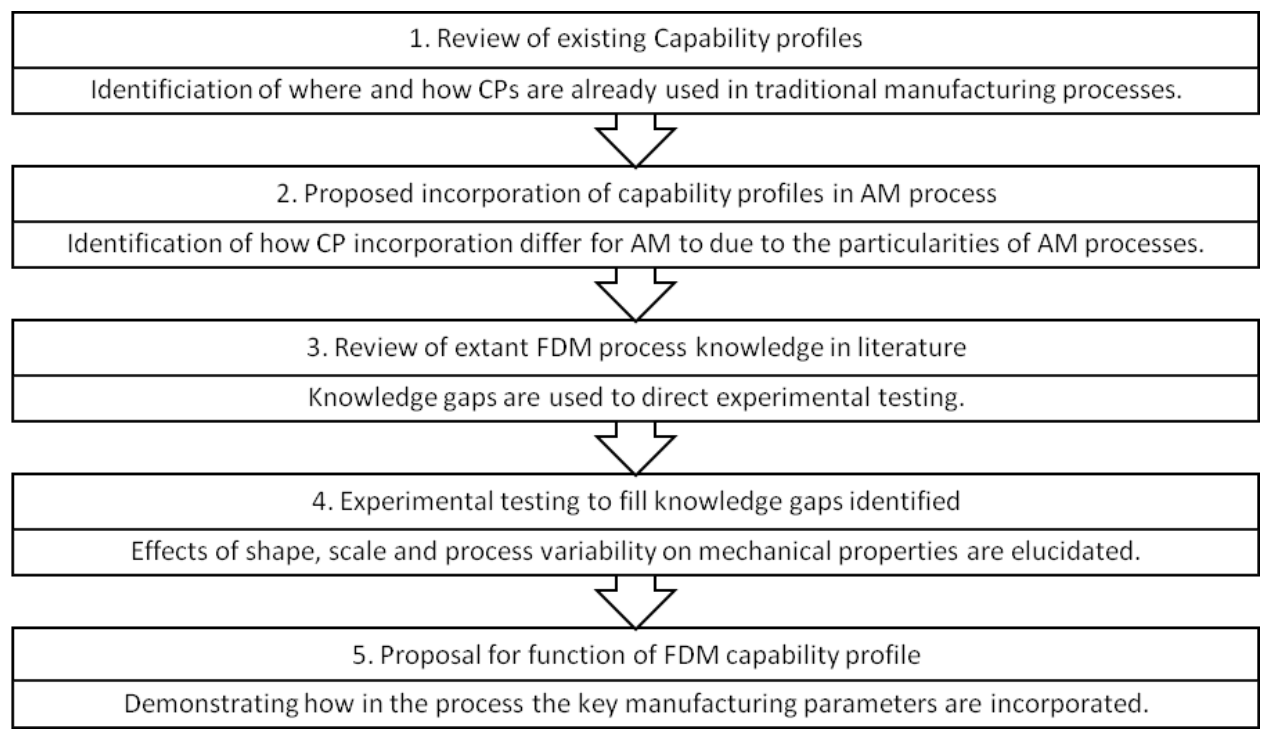

This paper begins with an overview of existing applications of capability profiles in traditional manufacturing processes. The FDM process is then presented and, based upon this, the incorporation of capability profiles in the AM design process is proposed. A comprehensive literature review is carried out to elucidate the impact of manufacturing parameters on the mechanical properties of parts manufactured by FDM. Knowledge gaps identified from this review are used to frame experimental testing which is undertaken to find the FDM process variability and effects of shape and scale on the 
mechanical behaviour of parts. Finally, this is drawn together to identify the key parameters required in a capability profile and a manner in which they can be incorporated is proposed. An overview of the paper methodology is shown in Figure 1.

\section{Existing capability profiles}

A capability profile is a time-sensitive image of a manufacturing resource, representing the capabilities that a specific machine tool will be able to provide at a specific time on a specific product (Newman and Nassehi, 2009). They relate the effect that machining parameters have on part properties by accounting for changes to the manufacturing resource over time. When this is coupled with information about the stock material and a part's geometry the characteristics of a workpiece can be described. This can take place at four levels ranging from geometry of the element to the chemical integration at the atomic scale (Klocke et al., 2005):

- macro (accuracy in shape and dimension)

- micro (surface topography)

- meso (material structure and properties)

- $\quad$ nano (tribo-chemical reaction layers).

Capability profiles can be incorporated in a number of ways within existing CAx chains to support the manufacturing process. The most common CAx chain used in manufacturing today involves the generation of a part in computer aided design (CAD) software. This is then transferred to a computer aided process planning (CAPP) or computer aided manufacturing (CAM) system where process information is added to the geometry. This information typically includes tool definitions, feeds, speeds and machining strategies. A post-processor is used to move the information from a product space in CAM to the machine space in the CNC (Newman and Nassehi, 2007). Within this process, CPs are typically used in process planning which consists of the consolidation of activities that seek to define the steps required to alter the shape of raw stock material into the desired product (ElMaraghy, 1993). The use of CPs allows the selection of appropriate manufacturing resources for a given part.

Figure 2 shows the process planning process incorporating manufacturing capability profiles. The manufacturing production resource is profiled by combining sensed data from the resource itself, nominal resource information and production policies. These allow tool wear to be measured and compared against an allowable threshold that would yield the manufacture of an acceptable part.

For traditional subtractive methods the development of a number of capability profiles can be found in existing literature including a capability profile for hard cutting and grinding (Klocke et al., 2005) and a review machining parameters in the turning process that effect finish part properties (Bartarya and Choudhury, 2012). Additionally the integrated use of manufacturing resource profiles is proposed in CAPP in order to optimise the generation of process plans (Newman and Nassehi, 2009). CPs are also used to provide a tool health data model (Vichare et al., 2015). 
Figure 2 IDEF-0 representation of process planning for subtractive process with manufacturing capability profiles (see online version for colours)

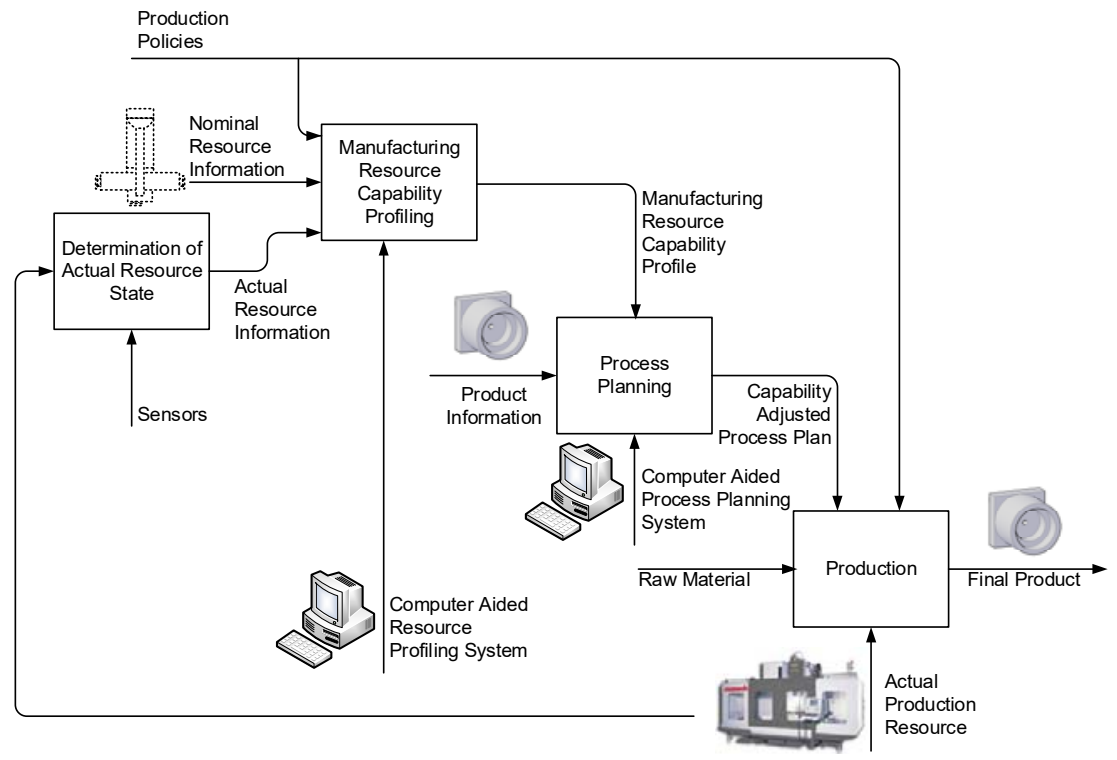

Source: Newman and Nassehi (2009) (reproduced with permission)

\section{Capability Profiles for FDM}

Capability profiles for traditional manufacturing methods are based upon mechanical properties of materials and the effect that various manufacturing processes have on these.

Emerging manufacturing technologies such as FDM offer far greater flexibility in manufacturing outcome than traditional subtractive processes. This enables the production of structures that would be impossible by traditional (mostly subtractive) manufacturing methods (Garrett, 2014) and also permits the internal structural optimisation of FDM parts for strength (Gopsill and Hicks, 2016), mass distribution (Prévost et al., 2013) and moment of inertia (Bächer et al., 2014). This flexibility is enabled by the additive, layer-wise deposition of material and the large number of manufacturing parameters that can be independently controlled in the generation of FDM tool paths. A number of key manufacturing parameters are demonstrated in Figure 3 and include build orientation, layer height, print speed, travel speed, extruder temperature, air gap, raster thickness, raster angle, number of solid shells, bed temperature and infill percentage. Whilst by no means an exhaustive list, they give an idea of the size and complexity of the solution space afforded by FDM, as well as an indication of the number of parameters that would need to be included in an FDM capability profile. 
Figure 3 Key FDM printing parameters (see online version for colours)

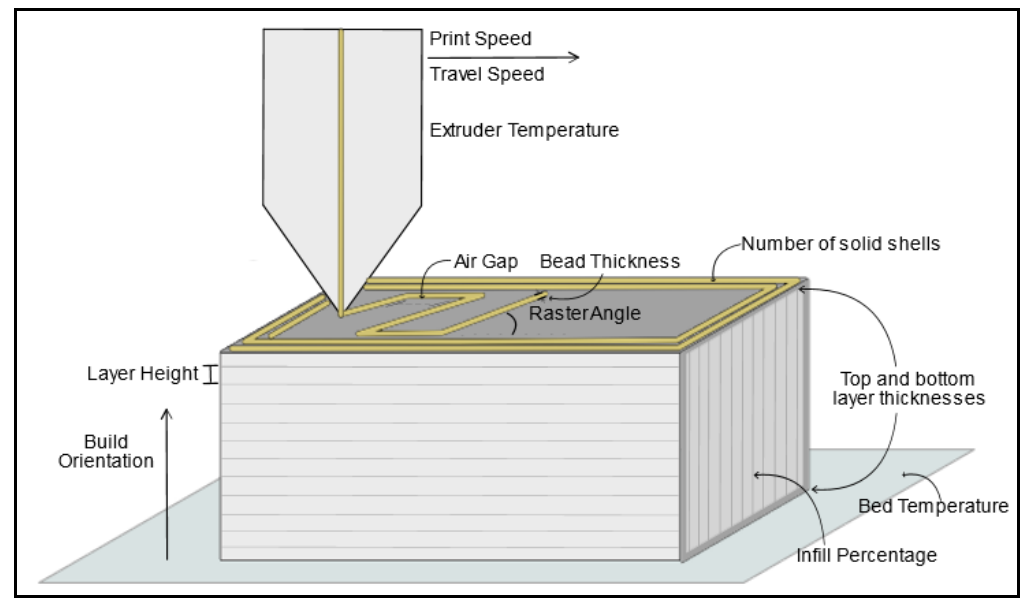

Figure 4 IDEF-0 representation of proposed incorporation of capability profile in design and manufacturing process for FDM

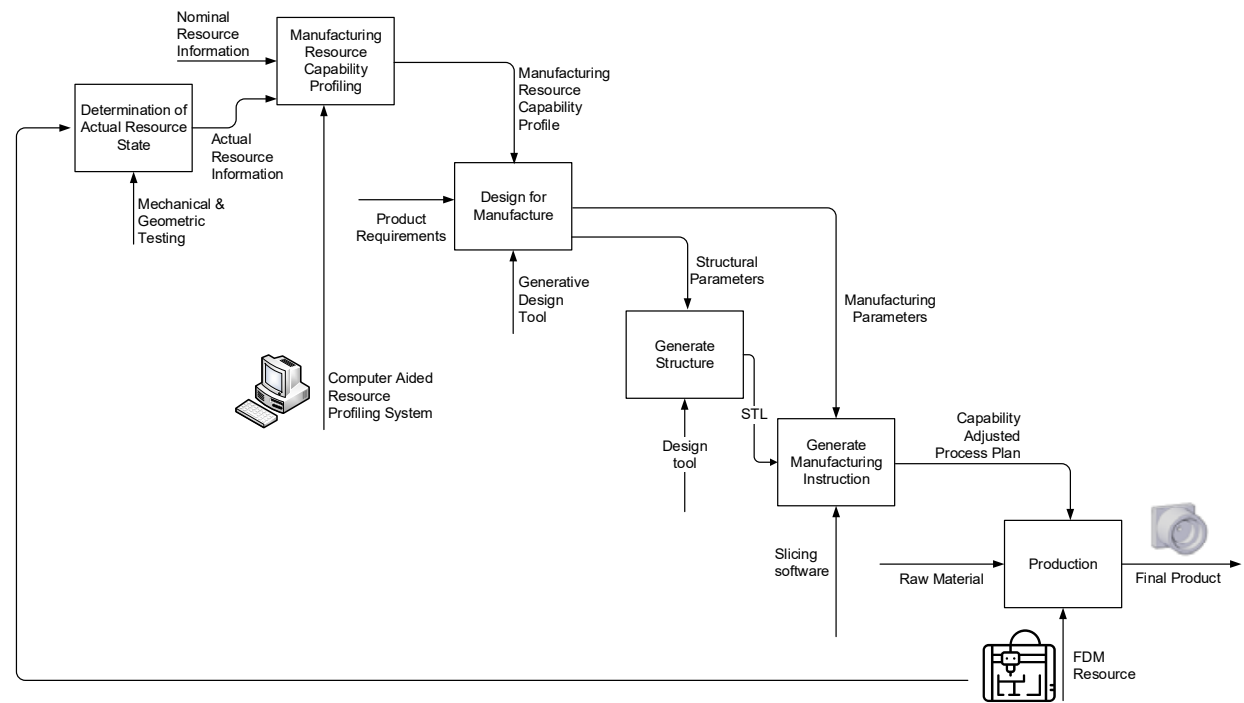

The manufacturing parameters therefore not only shape the manner in which the physical product is to be made, but also the very nature of the design itself. With respect to existing CAx chains, incorporation of manufacturing capability must be considered during the design process, not only in the CAPP or CAM stages. This is due to a drive towards 'built as designed' where products are expected to function and behave exactly as predicted (Potroucean et al., 2015) and also a more widespread uptake of generative 
design approaches such as that provided by Autodesk (Autodesk Inc, 2018). These generative approaches enable the generation of parts based upon functional requirements and manufacturing capability. As a result, a manufacturing resource capability profile shapes and directs the design of the part and therefore needs to be included earlier in the design and manufacturing process than with traditional CPs.

Figure 4 presents an IDEF-0 representation of how a capability profile for FDM would be determined and incorporated within a generative design process that concomitantly generates both manufacturing and structural parameters that permit a part to meet its functional requirements. Whilst it is not within the scope of this paper to explore the manner in which this could be achieved, an overview of such a process is presented in literature (Goudswaard et al., 2018).

The process planning for subtractive processes (Figure 2) uses the manufacturing resource capability as a control for the process planning stage to transform product information (such as a static CAD model) into a capability adjusted process plan. In the proposed process for FDM (Figure 4) however, it uses it as control to generate structural and manufacturing parameters based upon the object requirements. Manufacturing capability therefore has a direct influence on the design of a product, not just in the way it's manufactured, as it is necessary to exploit the flexibility of the process.

As shown in the IDEF representation (Figure 4), the mechanism for developing a capability profile for FDM would be via geometric and mechanical testing of parts. This is due to uncertainty surrounding parts manufactured via FDM which will be explored in greater detail in Section 4. Whilst sensing (such as for subtractive processes shown in Figure 1) might be appropriate in the future once the FDM process is better understood, for now physical testing of parts is the only way of developing a thorough understanding of a manufacturing resource's capability.

Having explored CPs for extant processes and proposed how they would be incorporated within the FDM process. The following section explores information about the manufacturing process that would need to be incorporated within $\mathrm{CP}$. In doing this, research gaps are identified which in turn direct testing that needs to be carried out to deduce this information.

\section{Existing FDM process knowledge}

Having identified the differing requirements of capability profiles for FDM compared to subtractive processes and alluded to the breadth of parameters that might need to be included in a CP for FDM, this section explores existing process knowledge for FDM. It allows the identification of extant empirical relationships between manufacturing parameters and mechanical properties which can be incorporated within a capability profile for FDM. It also permits gaps in existing research to highlighted in order to direct the undertaking of further experimental testing.

Early applications of FDM, as a manufacturing technology, were largely aesthetic or for prototyping, with a focus on high quality prints to generate consistent, geometrically accurate parts with good surface finishes but with little consideration of their functional performance. Consequently, various methods of geometric benchmarking have been proposed to assess these elements of an FDM printer's capability (Rebaioli and Fassi, 2017). 
As the technology has developed further and FDM has become more capable of producing structural parts, studies have sought to evaluate and characterise the relationship between mechanical properties and manufacturing parameters. From these studies a number of empirical relationships have been deduced:

1 studies of layer height have generally found that larger layers increase part strength (Tymrak et al., 2014; Onwubolu and Rayegani, 2014; Alafaghani et al., 2017; Croccolo et al., 2013; Sood et al., 2010; Lanzotti et al., 2015)

2 studies of part build orientation have revealed that parts are found to be weakest in the direction of build (Tymrak et al., 2014; Onwubolu and Rayegani, 2014; Alafaghani et al., 2017; Croccolo et al., 2013; Sood et al., 2010; Lanzotti et al., 2015)

3 parts are strongest with raster angle in direction of the applied load and increased raster width increases part strength (Onwubolu and Rayegani, 2014; Croccolo et al., 2013; Casavola et al., 2016; Sood et al., 2010; Lanzotti et al., 2015)

4 a negative air gap is found to increase part strength (Onwubolu and Rayegani, 2014; Croccolo et al., 2013; Sood et al., 2010)

5 an increased infill percentage is found to increase part strength (Alafaghani et al., 2017)

6 an increase in the number of solid shells increases part strength (Croccolo et al., 2013; Lanzotti et al., 2015)

7 extrusion temperature is shown to greatly affect the mechanical properties of the printed parts with distinct optimum extrusion temperature ranges existing for different materials (Alafaghani et al., 2017; Wittbrodt and Pearce, 2015)

8 mechanical properties are found to vary significantly with material type, build (Tymrak et al., 2014; Onwubolu and Rayegani, 2014) and colour (Wittbrodt and Pearce, 2015).

From the review of existing literature, a number of research gaps requiring addressing can be identified.

While the reported studies have established a number of empirical relationships, many used relatively small sample sizes of 3 (Onwubolu and Rayegani, 2014; Alafaghani et al., 2017; Sood et al., 2010; Lanzotti et al., 2015) or 5 (Croccolo et al., 2013; Casavola et al., 2016) with little reporting of the process variability, or identified very high variability in mechanical properties (Lanzotti et al., 2015) compared to the raw material (Casavola et al., 2016). As a consequence of this, while the empirical relatives are directed, no magnitudes have been established with any confidence. A research gap is therefore identified as the identification of the variation in ultimate tensile strength (UTS) for test pieces manufactured with identical material and process settings for a much larger sample size than those in previous studies. The need to clarify variability of the FDM process is specifically identified in a comprehensive review paper on the mechanical properties of parts manufactured via FDM (Popescu et al., 2018).

Additionally, existing studies have largely tested according to ASTM standards for material testing [tensile (ASTM International, 2003), compressive (ASTM, 2016) and Flexural (ASTM-D790-17, 2017)] and test the properties of the prescribed specimen which is assumed to be indicative of properties of other shapes and sizes made of the 
same material. This assumption is currently un-substantiated by experimental evidence, and due to the layer wise construction of the manufacturing process might not be valid. An additional research gap is therefore identified as eliciting the effect of shape and scale on the mechanical properties of parts.

Whilst a large number of empirical relationships between manufacturing parameters and mechanical properties, a variety of printers, polymers, slicing software and process parameters were used, meaning that the generalisation of existing results is very difficult (Popescu et al., 2018). It is therefore necessary to undertake a comprehensive testing regime on a single printer and material in order to determine conclusively the effect that all print parameters have on mechanical properties.

In light of these identified research gaps, the following sections detail experimental testing undertaken to determine the variation in UTS of tensile test specimens and also the effects of shape and scale on the mechanical properties of parts.

\section{Variance determination}

To determine the variance in mechanical properties of parts manufactured by FDM, tensile tests were undertaken with batch sizes larger than those found in existing literature.

Test specimens were manufactured on an Ultimaker 2 using Ultimaker branded silver metallic polylactic acid (PLA) filament. Tensile tests were undertaken on an Instron 3343 tensile test machine with loads measured with a $1 \mathrm{kN}$ Instron force transducer. Specimens were extended at a rate of $1 \mathrm{~mm} / \mathrm{min}$ until break. Figure 6(a) shows the batch manufacture of specimens, and Figure 6(b) the experimental test set-up.

Figure 5 Dimensions of test specimen for variance tensile tests

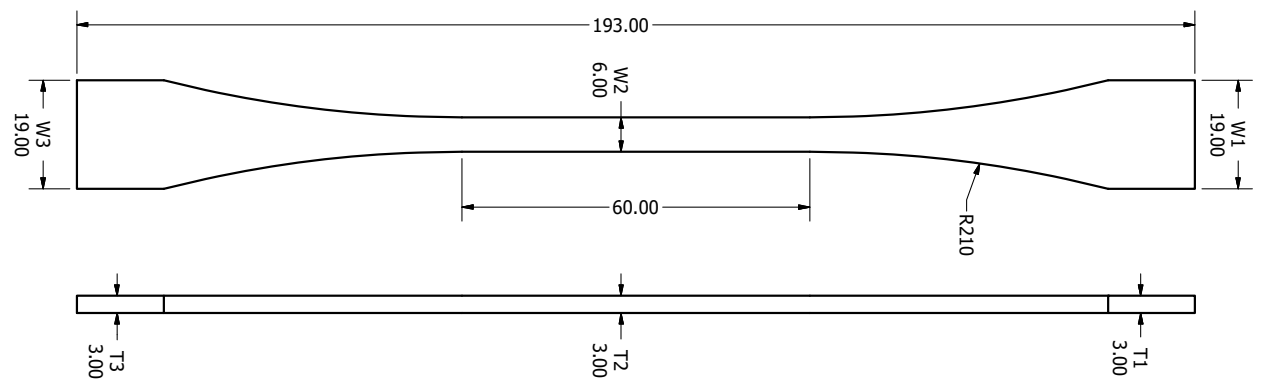

Note: Dimensions prefixed by W or T signify a measured width or thickness for each specimen. Gauge length is not shown as specimen extension was not measured.

Tests for variance determination used an altered ASTM:D638 (ASTM International, 2003) specimen (shown in Figure 5). A larger radius was added to reduce the likelihood of failure occurring outside of the reduced area [as also done by Croccolo et al. (2013)]. Specimen dimensions are shown in Figure 5. Eight batches of five samples were manufactured at infill values of $20 \%$ and $100 \%$. These two values represent the extremes with an infill below 20\% resulting in an inconsistent top layer (compromising the overall shell) and $100 \%$ infill resulting in a solid part which negates the effect of infill pattern. Other print parameters of layer height, wall thickness, top/bottom thickness, infill pattern, 
extruder temperature, print speed, travel speed, print cooling and print sequence were all kept constant across the batches.

Figure 6 (a) Picture of specimen manufacture (b) Tensile test set-up (see online version for colours)

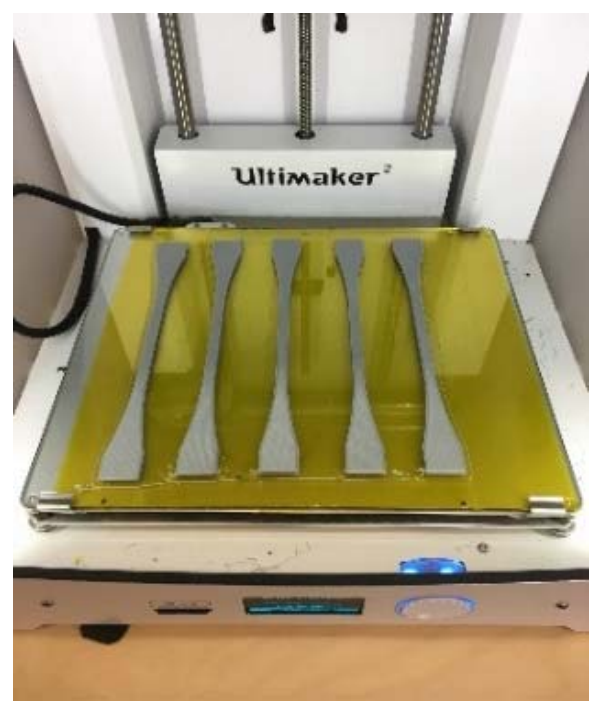

(a)

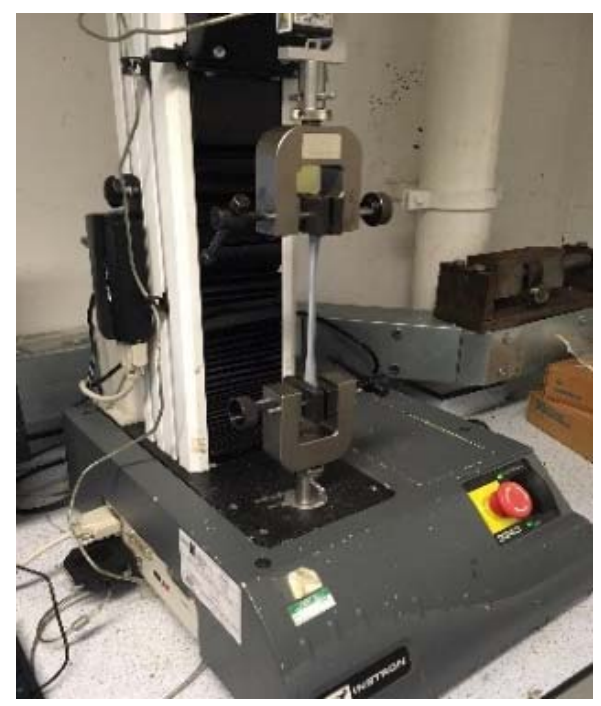

(b)

\subsection{Results}

Table 1 is an extract of the collective specimen measurements and the results taken during the tensile tests. Samples are considered collectively, and within the batches in which they were manufactured. Whilst all samples were printed with the same filament, different rolls were used for some of the samples. To account for any change in properties caused by this, additional samples were tested. For this reason, more sets of $100 \%$ infill specimens were tested than $20 \%$ infill -5 and 3 respectively.

Table 1 Results of tensile tests for variance determination

\begin{tabular}{lcccccccccc}
\hline SAMPLE & 1 & 2 & 3 & 4 & 5 & 6 & 7 & 8 & $\begin{array}{c}20 \% \\
\text { total }\end{array}$ & $\begin{array}{c}100 \% \\
\text { total }\end{array}$ \\
\hline Infill \% & 20 & 20 & 20 & 100 & 100 & 100 & 100 & 100 & 20 & $100 \%$ \\
Sample size & 5 & 5 & 5 & 5 & 5 & 5 & 5 & 5 & 15 & 25 \\
\hline Break Load (N) & 539 & 567 & 592 & 686 & 766 & 766 & 755 & 749 & 566 & 745 \\
SD (N) & 16.5 & 23.8 & 26.8 & 29.8 & 38.1 & 27.1 & 35.1 & 34.8 & 30.7 & 44.5 \\
\% range & 7 & 11 & 11 & 13 & 13 & 9 & 14 & 14 & 21 & 24 \\
Max (N) & 557 & 598 & 639 & 737 & 822 & 801 & 803 & 812 & 639 & 822 \\
Min (N) & 519 & 535 & 575 & 646 & 719 & 735 & 700 & 707 & 519.3 & 646.3 \\
Range (N) & 37.4 & 63.5 & 64.0 & 90.7 & 102 & 66.3 & 102 & 106 & 120 & 176 \\
\hline
\end{tabular}

Note: Standard deviation is abbreviated to $\mathrm{SD}$, percentage range is defined as the range divided by the mean expressed as a percentage 
Table 1 Results of tensile tests for variance determination (continued)

\begin{tabular}{|c|c|c|c|c|c|c|c|c|c|c|}
\hline SAMPLE & 1 & 2 & 3 & 4 & 5 & 6 & 7 & 8 & $\begin{array}{l}20 \% \\
\text { total }\end{array}$ & $\begin{array}{c}100 \% \\
\text { total }\end{array}$ \\
\hline UTS (Mpa) & 29.9 & 32.4 & 33.9 & 38.0 & 43.4 & 43.7 & 43.5 & 43.2 & 32.0 & 42.4 \\
\hline SD (MPa) & 0.4 & 1.4 & 1.9 & 1.1 & 1.9 & 1.3 & 2.4 & 2.4 & 2.12 & 2.94 \\
\hline$\%$ range & 4 & 12 & 14 & 8 & 12 & 7 & 17 & 17 & 24 & 26 \\
\hline $\operatorname{Max}(\mathrm{N})$ & 30.5 & 34.5 & 37.0 & 39.4 & 46.1 & 45.3 & 46.5 & 47.3 & 37.0 & 47.3 \\
\hline $\operatorname{Min}(\mathrm{N})$ & 29.4 & 30.7 & 32.3 & 36.2 & 41.0 & 42.1 & 39.2 & 39.9 & 29.4 & 36.2 \\
\hline Range (N) & 1.1 & 3.8 & 4.7 & 3.2 & 5.1 & 3.2 & 7.3 & 7.4 & 7.6 & 11.1 \\
\hline $\mathrm{W} 2$ (mm) & 6.02 & 6.03 & 6.01 & 6.04 & 6.03 & 6.03 & 5.98 & 5.95 & 6.02 & 6.01 \\
\hline $\mathrm{SD}(\mathrm{mm})$ & .019 & .013 & .023 & .016 & .018 & .015 & .040 & .022 & .018 & .045 \\
\hline$\%$ Range & .66 & .5 & 1 & .66 & .83 & .7 & 1.7 & 1 & 1.0 & 2.3 \\
\hline $\operatorname{Max}(\mathrm{mm})$ & 6.04 & 6.04 & 6.05 & 6.05 & 6.06 & 6.05 & 6.04 & 5.98 & 6.1 & 6.1 \\
\hline $\operatorname{Min}(\mathrm{mm})$ & 6 & 6.01 & 5.99 & 6.01 & 6.01 & 6.01 & 5.94 & 5.92 & 6.0 & 5.9 \\
\hline $\mathrm{T} 2$ (mm) & 3.00 & 2.90 & 2.90 & 2.99 & 2.92 & 2.91 & 2.91 & 2.92 & 2.93 & 2.93 \\
\hline $\mathrm{SD}(\mathrm{mm})$ & .067 & .036 & .048 & .059 & .027 & .022 & .063 & .041 & .066 & .055 \\
\hline$\%$ Range & 5.0 & 2.8 & 3.8 & 5.4 & 2.4 & 2.1 & 5.8 & 3.8 & 8 & 9 \\
\hline $\operatorname{Max}(\mathrm{mm})$ & 3.09 & 2.96 & 2.97 & 3.09 & 2.95 & 2.94 & 3.01 & 2.99 & 3.1 & 3.1 \\
\hline $\operatorname{Min}(\mathrm{mm})$ & 2.94 & 2.88 & 2.86 & 2.93 & 2.88 & 2.88 & 2.84 & 2.88 & 2.9 & 2.8 \\
\hline Mass (g) & 5.05 & 4.93 & 4.98 & 6.79 & 6.77 & 6.76 & 6.78 & 6.83 & 4.98 & 6.78 \\
\hline $\mathrm{SD}(\mathrm{g})$ & 0.12 & 0.08 & 0.07 & 0.15 & 0.09 & 0.08 & 0.02 & 0.02 & 0.100 & 0.083 \\
\hline$\%$ Range & 5 & 4 & 4 & 5 & 3 & 3 & 1 & 1 & 8 & 5 \\
\hline $\operatorname{Max}(\mathrm{g})$ & 5.19 & 5.03 & 5.09 & 6.96 & 6.89 & 6.88 & 6.80 & 6.86 & 5.2 & 7.0 \\
\hline $\operatorname{Min}(g)$ & 4.92 & 4.81 & 4.89 & 6.62 & 6.66 & 6.65 & 6.75 & 6.81 & 4.8 & 6.6 \\
\hline
\end{tabular}

Note: Standard deviation is abbreviated to SD, percentage range is defined as the range divided by the mean expressed as a percentage

\subsection{Discussion}

The different samples demonstrated tensile strengths ranging by $24 \%$ to $26 \%$ percent when considered collectively and $4 \%$ to $17 \%$ intra-batch. This section explores the impact of extruder temperature fluctuations, whether the variability can be correlated to other part properties, and lastly how knowledge (characterisation) of this variability can be used when designing parts for manufacture via FDM.

\subsubsection{Thermal imagine of FDM process}

An exploratory study was carried out to investigate fluctuations in extruder temperature as a possible cause of the variation in tensile strengths for the identical samples. This was investigated as Alafaghani et al. (2017) found that changing the extrusion temperature set point resulted in significant alterations in tensile strength (shown in Table 2). It has also previously been identified that filament temperature is a critical parameter in dictating 
part strength (Sun et al., 2008). This study sought to identify how the extruder temperature fluctuates around the set point during the duration of a print.

Table 2 UTS vs. extrusion temperature

\begin{tabular}{lcc}
\hline Extrusion temperature $\left({ }^{\circ} \mathrm{C}\right)$ & UTS $(\mathrm{MPa})$ & $\%$ change from $180^{\circ} \mathrm{C}$ \\
\hline 175 & 28.59 & $-30 \%$ \\
180 & 40.58 & $0 \%$ \\
185 & 46.06 & $14 \%$ \\
205 & 43.79 & $8 \%$ \\
\hline
\end{tabular}

Source: Alafaghani et al. (2017)

This effect was explored by analysing the change in extruder temperature during the print using a FLIR T650sc thermal imaging camera. A test piece of a single raster width was manufactured under the same conditions as those in the manufacture of the tensile test specimens and was filmed at 30 frames per second. The video was then analysed using FLIR IR Tools + software. Average, maximum and minimum temperatures were extracted from four regions: deposited filament $(\mathrm{Bx} 2)$; high in the nozzle $(\mathrm{Bx} 3)$; mid nozzle $(\mathrm{Bx} 4)$ and nozzle exit $(\mathrm{Bx} 5)$. These regions are shown in Figure 7.

Figure 7 IR image of extruder during print showing areas in which temperatures were measured (see online version for colours)

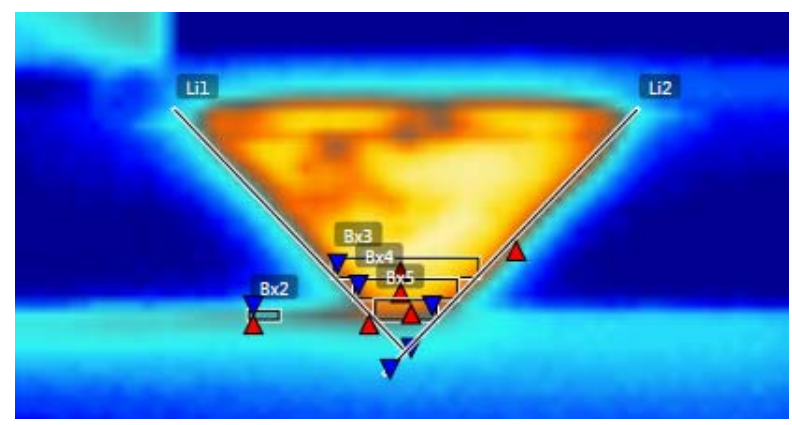

Table 3 shows the measured results for temperature fluctuations in these areas. Over the course of a print the high and mid nozzle areas show roughly $2{ }^{\circ} \mathrm{C}$ changes whilst the deposited filament and nozzle exit areas show fluctuations of almost $5^{\circ} \mathrm{C}$. When coupled with the temperature effects shown in Table 2 , a $5^{\circ} \mathrm{C}$ temperature fluctuation could give rise to a $14-30 \%$ change in UTS. Therefore, correlation is observed between extruder temperature fluctuations and UTS, suggesting temperature fluctuations could be a cause of the variation in mechanical properties.

Table 3 Measured temperature fluctuations during print

\begin{tabular}{lcc}
\hline & Mean $\left({ }^{\circ} \mathrm{C}\right)$ & Range $\left({ }^{\circ} \mathrm{C}\right)$ \\
\hline Bx2 - Deposited filament & 99.08 & 4.1 \\
Bx3 - High nozzle & 196.87 & 2.2 \\
Bx4 - Mid nozzle & 186.03 & 2.4 \\
Bx5 - Nozzle exit & 150.92 & 4.8 \\
\hline
\end{tabular}


Figure 8 Scatter plot showing stochastic relationship between UTS and other part properties (see online version for colours)

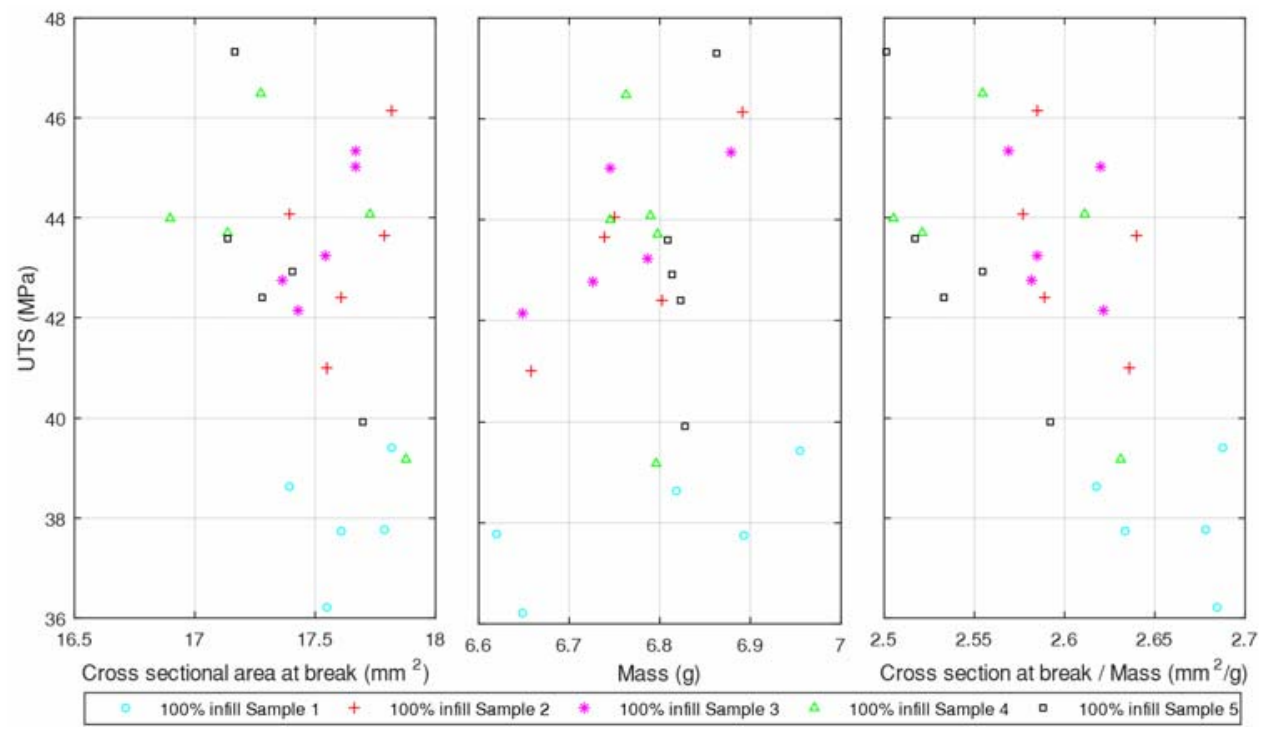

\subsubsection{Relationships between part properties and load}

Given the large range of experimentally determined tensile strengths, analysis was carried out to elicit whether there existed any relationship between other part properties and tensile strength. The other part properties explored were cross sectional area at break, part mass and the cross section at break divided by the mass. These were selected as their measurements were found to vary significantly in the test specimens and are properties that can be measured non-destructively. This is important because if a relationship were to be found it would allow the correlation and hence prediction of a part property that could otherwise only be determined through destructive testing.

Scatter plots showing their respective relationships against UTS for the $100 \%$ infill samples are given in Figure 8. All the relationships can be observed to be stochastic signifying that the UTS cannot be reliably correlated with the considered part properties (cross-sectional area and mass). A similar relationship was observed for the samples with $20 \%$ infill.

\subsubsection{Applying the findings to design tasks}

Given the high variability in tensile strengths and that these cannot be correlated to other part properties, a statistical model can be developed to predict the likelihood of a designed part meeting a defined strength requirement. This section highlights how such a model was developed based upon the results of the $100 \%$ infill test samples.

A Shapiro-Wilk test for normality (Shapiro and Wilk, 1965) was carried out on the break loads and UTSs of all the $100 \%$ infill samples. When considered both individually and collectively the sample sets were found to be normally distributed with means and standard deviations as defined in Table 1. Probability density functions can then be generated for the $100 \%$ infill samples. These are shown in Figure 9 for sample UTS. 
These can be used to predict the likelihood a design will meet a given requirement. It can be noted that one of the curves (sample 1) is significantly further to the left than the others. We believe that it is attributed to a change in filament roll during the manufacture of the specimens.

With respect to the formation of a CP for FDM, a statistical model, such as the one proposed, can be used within a capability profile to provide a confidence level that a part manufactured will have the required mechanical properties.

Figure 9 Probability density functions for UTS of $100 \%$ infill specimens (see online version for colours)

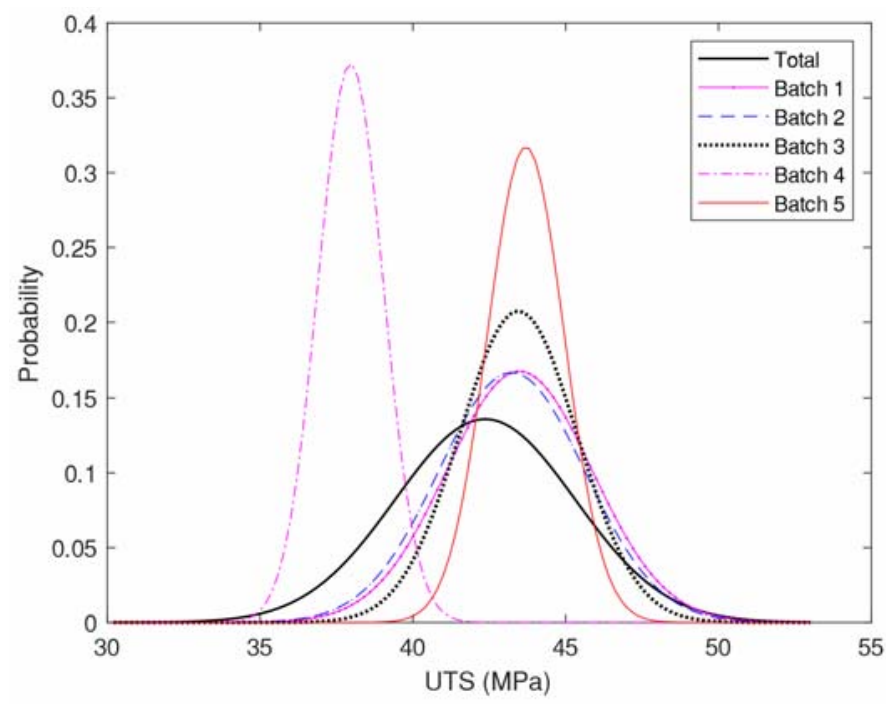

\subsubsection{Concluding remarks}

The section has presented experimental testing results that permit the elucidation of the variability of FDM process. Results suggest that this is caused by extruder temperature fluctuations during manufacture.

The presented statistical models enable the prediction of part properties. These can be directly used within a CP for FDM as they allow the prediction of variety of outcome that can be expected in the manufacture of a part.

\section{Shape and scale effect determination}

As stated in Section 4, it is currently unclear whether the mechanical properties of FDM parts are consistent with respect to shape and scale. The aim of these tests was therefore to elicit the significance of shape and scale on the mechanical properties of parts, in order to understand if they need to be included in a CP for FDM. To determine the effect of shape tensile tests were carried out on samples with different cross sections but constant area. To determine the effect of scale, tests were carried out on samples with the same cross section but different areas. 
Tensile tests were undertaken on an Instron 3343 tensile test machine with loads measured with a $1 \mathrm{kN}$ Instron force transducer. Specimens were extended at a rate of $1 \mathrm{~mm} / \mathrm{min}$ until break.

Six batches of six specimens were manufactured on an Ultimaker 2 with Ultimaker branded silver PLA. All samples were printed with the same reel of filament.

An amended test specimen was used for these tests compared to that which was used to deduce the effect of variance. This was to enable a significant variance in cross-sectional shape and area, whilst simultaneously permitting variance of the solid shells printing parameter which can only be varied in discrete increments of nozzle size ( $0.4 \mathrm{~mm}$ for the tests carried out). The cross sections manufactured are shown in Figure 10 .

The first set of specimens concerned with shape all used identical printing parameters, a constant cross sectional areal with rectangular, circular and triangular cross sections respectively (shown in Figure 10).

Figure 10 Sample cross sections for determining effect of shape
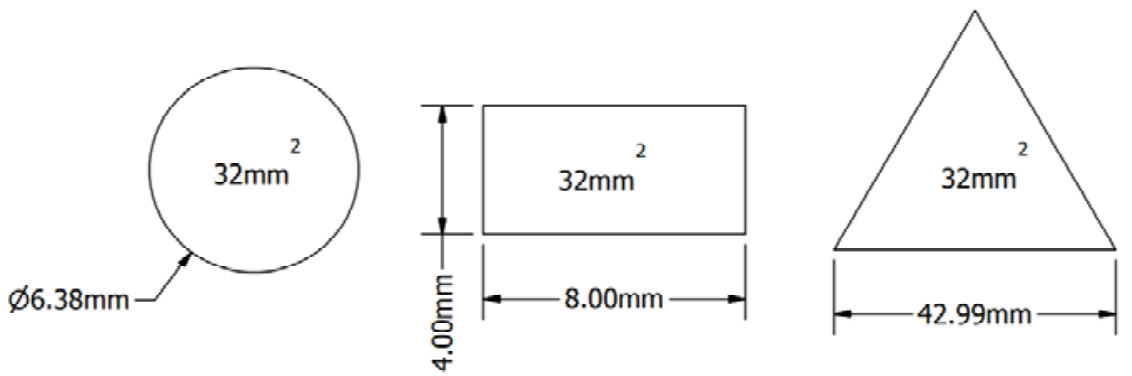

The second set of specimens used a rectangular cross section of varying area but constant aspect ratio. Identical manufacturing parameters were used with the exception of the $1 / 2$ scaled rectangular cross section which also scaled the solid shells parameter in line with the cross section. These cross-sections are shown in Figure 11.

Figure 11 Cross sections of tested samples for determining effect of scale
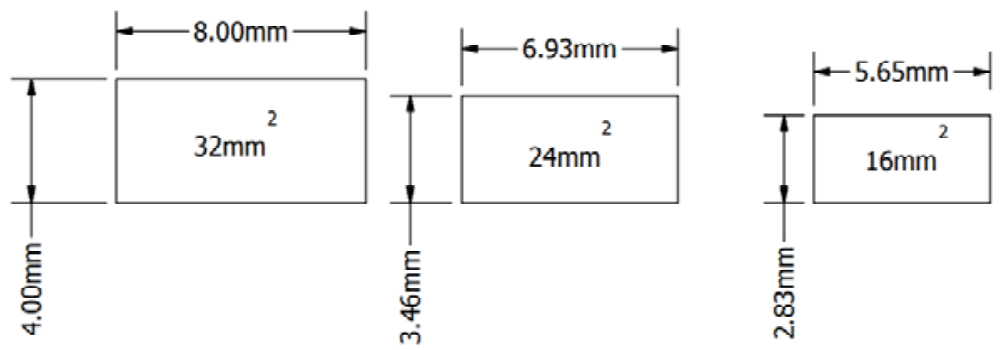

The reduced area section was reduced in length when compared with ASTM specimen in order to ensure break occurred within the length of the extensometer $(50 \mathrm{~mm})$. A plan of the test specimen is shown in Figure 12. 
Figure 12 Dimensions of test specimen for shape and scale testing

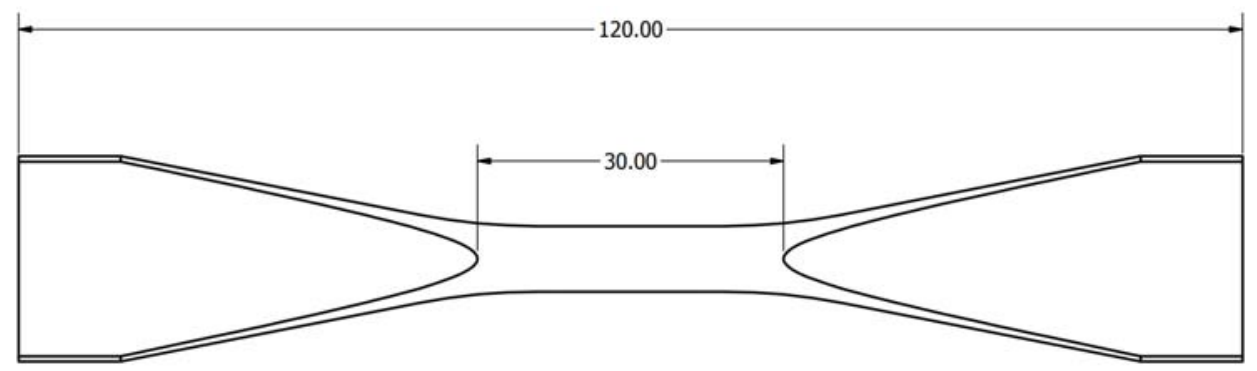

\subsection{Results}

Results of the tests carried out to deduce the effects of shape and scale are shown in Table 4. A moderate variation ( $9 \%$ with respect to UTS) can be observed due to the effect of cross section shape, and a much more significant variation ( $38 \%$ with respect to UTS) can be observed due to the effect of scale. It is noteworthy that maximum break load does not scale linearly with the size of the part.

Table 4 Results of tensile testing to explore the effects of shape and scale

\begin{tabular}{|c|c|c|c|c|c|c|}
\hline Sample & 1 & 2 & 3 & 4 & 5 & 6 \\
\hline Scale & $3 / 4$ & $1 / 2$ & $1 / 2$ & 1 & 1 & 1 \\
\hline $\begin{array}{l}\text { Top/bottom layer thickness and } \\
\text { number of solid shells (mm) }\end{array}$ & 0.8 & 0.4 & 0.8 & 0.8 & 0.8 & 0.8 \\
\hline Cross section shape & Rectangle & Rectangle & Rectangle & Rectangle & Circle & Triangle \\
\hline Break load (N) & 800.5 & 382.9 & 604.6 & 876.4 & 906.4 & 956.7 \\
\hline $\begin{array}{l}\% \text { difference when compared } \\
\text { to control }\end{array}$ & $-9 \%$ & $-56 \%$ & $-31 \%$ & $N / A$ & $3 \%$ & $9 \%$ \\
\hline $\mathrm{SD}(\mathrm{N})$ & 27.4 & 7.7 & 23.5 & 29.4 & 39.0 & 37.4 \\
\hline Range (N) & 75.3 & 16.9 & 65.2 & 80.2 & 107.9 & 85.1 \\
\hline$\%$ Range & $9 \%$ & $4 \%$ & $11 \%$ & $9 \%$ & $12 \%$ & $9 \%$ \\
\hline Area $\left(\mathrm{mm}^{2}\right)$ & 24.0 & 16.0 & 16.0 & 32.0 & 32.0 & 32.0 \\
\hline $\begin{array}{l}\% \text { difference when compared } \\
\text { to control }\end{array}$ & $-25 \%$ & $-50 \%$ & $-50 \%$ & $N / A$ & $0 \%$ & $0 \%$ \\
\hline UTS (MPa) & 33.4 & 23.9 & 37.8 & 27.4 & 28.3 & 29.9 \\
\hline $\begin{array}{l}\% \text { difference when compared } \\
\text { to control }\end{array}$ & $22 \%$ & $-13 \%$ & $38 \%$ & $N / A$ & $3 \%$ & $9 \%$ \\
\hline
\end{tabular}

Note: Standard deviation is abbreviated to SD, percentage range is defined as the range divided by the mean expressed as a percentage. Baseline refers to sample 4 .

\subsection{Discussion}

Having identified nonlinearity in mechanical performance caused by scale and variance due to cross-sectional shape it is important to identify a possible cause for the variation. 
The ratio of solid shells to infill can be observed to have a significant impact on a specimen's tensile properties. This can be attributed to the observed nonlinearity of the ratio as the specimens are scaled. It is suggested in existing literature that solid shells contribute more to part strength than infill (Goudswaard et al., 2018). Two identical cross-sections with different ratios of infill to solid shell would therefore exhibit different mechanical performance. This is demonstrated in the presented testing results. Table 5 demonstrates how the ratio of shell to infill changes as rectangular test specimens are scaled. When maintaining a constant top/bottom layer and solid shells thickness the ratio can be observed to vary from $1.08: 1$ to $2.21: 1$.

Table 5 Effect of scale on ratio of infill to solid shell

\begin{tabular}{lcccccc}
\hline Sample & $\begin{array}{c}\text { Cross section } \\
\text { area }\left(\mathrm{mm}^{2}\right)\end{array}$ & $\begin{array}{c}\text { Top/bottom } \\
\text { layer and } \\
\text { solid shells }\end{array}$ & $\begin{array}{c}\text { Shell area } \\
\left(\mathrm{mm}^{2}\right)\end{array}$ & $\begin{array}{c}\text { Infill area } \\
\left(\mathrm{mm}^{2}\right)\end{array}$ & $\begin{array}{c}\text { Ratio } \\
\text { shell:infill }\end{array}$ & $\begin{array}{c}\text { Break } \\
\text { load }(\mathrm{N})\end{array}$ \\
\hline 4 & 32.0 & 0.8 & 16.6 & 15.4 & $1.08: 1$ & 876.4 \\
1 & 24.0 & 0.8 & 14.1 & 9.9 & $1.42: 1$ & 800.5 \\
2 & 16.0 & 0.4 & 6.1 & 9.8 & $0.62: 1$ & 382.9 \\
3 & 16.0 & 0.8 & 11.0 & 5.0 & $2.21: 1$ & 604.6 \\
\hline
\end{tabular}

Whilst the ratio of infill to solid shell is found to have a significant effect when parts are scaled, when explored as a cause for the observed variation in mechanical performance due to change in cross sectional shape, the ratio of shell to infill cannot be directly identified as a cause. Although the geometric changes do alter the ratio of solid shell to infill (as can be seen in Table 6), no clear relationship can be observed. A number of other factors could contribute to the differing mechanical performance, including part cooling and stress concentrations accelerating failure of the specimens.

Table 6 Effect of shape on ratio on infill to solid shell

\begin{tabular}{lcccccc}
\hline Sample & $\begin{array}{c}\text { Cross section } \\
\text { area }\left(\mathrm{mm}^{2}\right)\end{array}$ & Shape & $\begin{array}{c}\text { Shell area } \\
\left(\mathrm{mm}^{2}\right)\end{array}$ & $\begin{array}{c}\text { Infill area } \\
\left(\mathrm{mm}^{2}\right)\end{array}$ & $\begin{array}{c}\text { Ratio } \\
\text { shell:infill }\end{array}$ & $\begin{array}{c}\text { Break load } \\
(\mathrm{N})\end{array}$ \\
\hline 4 & 32.0 & Rectangle & 16.64 & 15.36 & $1.08: 1$ & 876.4 \\
5 & 32.0 & Circle & 17.97 & 14.03 & $0.78: 1$ & 906.4 \\
6 & 32.0 & Triangle & 16.03 & 15.97 & $1: 1$ & 956.7 \\
\hline
\end{tabular}

\subsubsection{Concluding remarks}

Cross sectional shape does have an effect on the mechanical performance of the components and is shown to causes variation in UTS of 3\% to $9 \%$. A precise cause for this is not identified. The effect of scale is significant, and mechanical properties are shown to have a nonlinear relationship with cross-sectional area. This is attributed to the differing ratios of solid shell to infill as the parts are scaled.

\section{Developing an FDM capability profile}

The paper so far has posited a manner in which capability profiles can be incorporated into the design for FDM process, reviewed existing knowledge surrounding the 
manufacturing process itself and presented results from experimental testing to expand this extant knowledge. This section explores what process knowledge is necessary for a capability profile and how this can be drawn together to enable the prediction of a part's mechanical behaviour based upon an input geometry and manufacturing parameters. The parameters included are those identified from literature as having a significant impact on properties of finished parts and also those that need to be defined by the user in the slicing processes. These parameters can thus be divided into three groups according to the nature of the impact they have on the manufactured part:

- group 1 consists of those that directly affect a part's behaviour by altering the mechanical properties (such as UTS or Young's Modulus)

- group 2 consists of parameters that affect the post-slice geometry and thus alter the shape properties of parts

- $\quad$ group 3 includes those parameters that affect both of the above (layer height for example alters the UTS but also influences the way geometry is sliced).

Essential manufacturing parameters for a capability profile are shown in Table 7. These are assigned one of the three parameter groups defined above and also a description as to how mechanical behaviour is influenced by the parameter. Indicative trends from literature are also included.

Table 7 How manufacturing parameters are incorporated into an FDM capability profile (see online version for colours)

\begin{tabular}{|c|c|c|c|c|}
\hline Parameter & $\begin{array}{l}\text { Affects material } \\
\text { property? }\end{array}$ & Affects sliced geometry? & $\begin{array}{l}\text { Indicative trend } \\
\text { from literature }\end{array}$ & $\begin{array}{l}\text { Parameter } \\
\text { group }\end{array}$ \\
\hline Layer height & $\begin{array}{l}\text { Yes. Increase in layer } \\
\text { height increases } \\
\text { strength }\end{array}$ & $\begin{array}{l}\text { Yes - vertical dimensions } \\
\text { are discretised in } \\
\text { increments of layer height }\end{array}$ & $\begin{array}{l}\text { Linear increase } \\
\text { (Alafaghani } \\
\text { et al., 2017) }\end{array}$ & 3 \\
\hline $\begin{array}{l}\text { Build } \\
\text { orientation }\end{array}$ & $\begin{array}{l}\text { Yes - properties vary } \\
\text { in different } \\
\text { orientations }\end{array}$ & $\begin{array}{c}\text { Yes - directional } \\
\text { discretisation varies } \\
\text { depending on build } \\
\text { direction }\end{array}$ & $\begin{array}{l}\text { Discrete } \\
\text { (Alafaghani } \\
\text { et al., 2017) }\end{array}$ & 3 \\
\hline Raster angle & $\begin{array}{l}\text { Yes - greater strength } \\
\text { when raster is in } \\
\text { direction of applied } \\
\text { load }\end{array}$ & - & $\begin{array}{l}\text { Linear increase } \\
\text { (Onwubolu and } \\
\text { Rayegani, 2014) }\end{array}$ & 1 \\
\hline Raster width & - & $\begin{array}{l}\text { Yes - affects solid shells as } \\
\text { these must be in } \\
\text { increments of raster width }\end{array}$ & $\begin{array}{l}\text { Linear increase } \\
\text { (Onwubolu and } \\
\text { Rayegani, 2014) }\end{array}$ & 2 \\
\hline Infill pattern & $\begin{array}{l}\text { Yes - gives varied } \\
\text { properties in different } \\
\text { directions }\end{array}$ & - & $\begin{array}{l}\text { Discrete } \\
\text { (Alafaghani } \\
\text { et al., 2017) }\end{array}$ & 1 \\
\hline $\begin{array}{l}\text { Infill } \\
\text { percentage }\end{array}$ & - & $\begin{array}{l}\text { Yes - affects amount and } \\
\text { distribution of material }\end{array}$ & $\begin{array}{l}\text { Linear increase } \\
\text { (Alafaghani } \\
\text { et al., 2017) }\end{array}$ & 2 \\
\hline $\begin{array}{l}\text { Top/bottom } \\
\text { layers }\end{array}$ & - & $\begin{array}{l}\text { Yes - affects amount and } \\
\text { distribution of material }\end{array}$ & $\begin{array}{l}\text { Quadratic/ } \\
\text { quartic }\end{array}$ & 2 \\
\hline
\end{tabular}

Note: Row colours correspond to parameter group 
Table 7 How manufacturing parameters are incorporated into an FDM capability profile (continued) (see online version for colours)

\begin{tabular}{|c|c|c|c|c|}
\hline Parameter & $\begin{array}{l}\text { Affects material } \\
\text { property? }\end{array}$ & Affects sliced geometry? & $\begin{array}{l}\text { Indicative trend } \\
\text { from literature }\end{array}$ & $\begin{array}{l}\text { Parameter } \\
\text { group }\end{array}$ \\
\hline Solid shells & - & $\begin{array}{l}\text { Yes - affects amount and } \\
\text { distribution of material }\end{array}$ & $\begin{array}{l}\text { Quadratic/ } \\
\text { quartic }\end{array}$ & 2 \\
\hline $\begin{array}{l}\text { Extrusion } \\
\text { temperature }\end{array}$ & $\begin{array}{l}\text { Yes - affects quality of } \\
\text { raster adhesion }\end{array}$ & No & $\begin{array}{l}\text { Parabolic } \\
\text { (Alafaghani } \\
\text { et al., 2017) }\end{array}$ & 1 \\
\hline Material type & $\begin{array}{c}\text { Yes }- \text { distinct } \\
\text { properties for different } \\
\text { materials }\end{array}$ & - & $\begin{array}{c}\text { Discrete } \\
\text { (Wittbrodt and } \\
\text { Pearce, 2015) }\end{array}$ & 1 \\
\hline Variability & $\begin{array}{c}\text { Yes - distribution } \\
\text { distinct for printers and } \\
\text { materials }\end{array}$ & - & $\begin{array}{c}\text { Normal } \\
\text { distribution } \\
\text { Section } 5.2 .3\end{array}$ & 1 \\
\hline Geometry & - & $\begin{array}{l}\text { Yes - affects ratio of solid } \\
\text { shell and top/bottom layers } \\
\text { to infill }\end{array}$ & $\begin{array}{l}\text { Quadratic/ } \\
\text { quartic }\end{array}$ & 2 \\
\hline
\end{tabular}

Note: Row colours correspond to parameter group

Figure 13 IDEF0 diagram of how capability profile uses manufacturing parameters to calculate mechanical behaviour

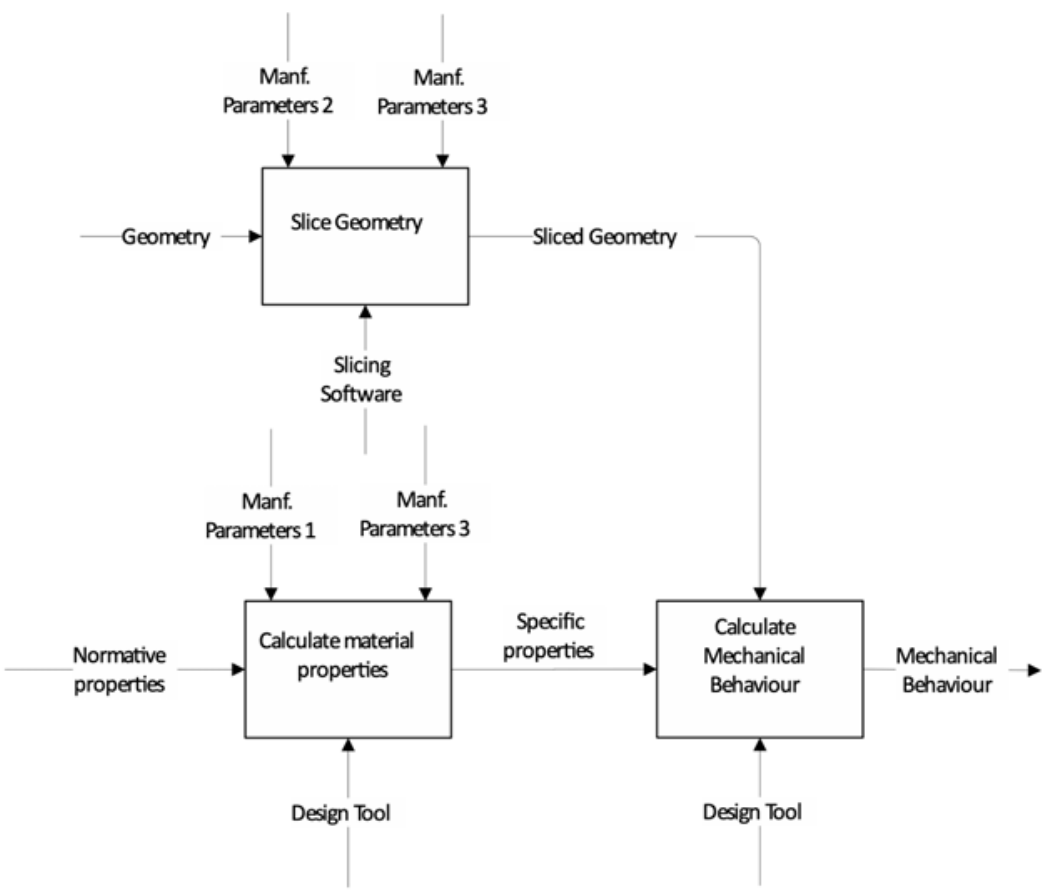

Figure 13 shows an IDEF0 diagram of how the defined groups of manufacturing parameters are used to elicit a part's mechanical behaviour. Specific material properties are calculated by adjusting a normative set of properties with the effects caused by 
manufacturing parameter groups 1 and 3 and are defined for both infill and solid shells respectively. Part geometry is sliced incorporating manufacturing parameter groups 2 and 3. The sliced geometry provides area moments and quantities of material for both infill and solid shells. When combined with the specific material properties these enable the prediction of a part's mechanical behaviour.

\section{Discussion and further work}

The use of capability profiles in the design process for FDM can enable the democratisation of design by involving non-technical stakeholders in the design process, whilst leveraging the large design space afforded by FDM and other AM technologies. Two important questions to consider with respect to the implementation of CPs for FDM is how would they be generated and by who?

Because of the size of the FDM design space and the large, ever-increasing variety of printers and materials available, the creation of capability profiles would need to be undertaken in two phases. General capability profiles would need to be created by printer manufacturers (experts) for particular types of printers, these would then be refined collaboratively by the crowd (non-experts) to account for printer-specific variation manufacturing capability. This approach to $\mathrm{CP}$ generation leverages the affordances of both experts and the crowd respectively.

Generalised capability profiles would be created by printer manufacturers and would involve mechanical testing of the parameters that have been identified in this paper. These would be carried out by 'expert' design, structural and manufacturing engineers. The relationships between parameters would be established and these would form the basis for a model that would be able to predict a part's mechanical behaviour. These relationships would however require refinement in order to enable the fabrication of repeatable and reliable parts on a specific printer.

This refinement could be carried out via means of a simple structural benchmarking artefact that could be manufactured and tested for mechanical performance. This would be similar to existing geometric benchmarking artefacts, such as Benchy (http://www.3dbenchy.com/), that are used to assess a 3D printer's geometric capability. The manufacture and test of a structural test piece would permit comparison of the performance of an actual printed part to that predicted by the general $\mathrm{CP}$. The results of these tests are then incorporated as correction factors within the general $\mathrm{CP}$, allowing it to be individualised. Thus, providing a user with an accurate $\mathrm{CP}$ specific to their printer. Interpreting and incorporating the results from testing these artefacts would be carried out by 'non-experts' from the crowd. Existing crowd-sourcing platforms such as Mechanical Turk (Amazon, 2017) or design repositories such as Thingiverse (MakerBot, 2019) could provide suitable environments for generating and sharing necessary information.

Through review of existing literature and the experimental work undertaken in this paper, there is a need to review the testing procedures used to determine the mechanical characteristics of FDM parts. Existing testing strategies are based upon the determination of mechanical properties. But given that these properties are not consistent for shape or size, amended test procedures are necessary to permit better elucidation of the effect of manufacturing parameters on mechanical properties. The design of an appropriate functional test piece would allow the assessment of the effect of manufacturing 
parameters, rather than the current methods which are used to determine the mechanical properties of the material rather than the specimen.

With respect to continuing further work, in this paper existing empirical studies from literature have been drawn together and complemented with further experimental testing in order to work towards a comprehensive capability profile for FDM. As has already been stated, much work already carried out has used a wide variety of polymers, printers, slicing software and process parameters making it difficult to generalise the findings (Popescu et al., 2018). Further work to be undertaken therefore will look to undertake an extensive testing regime on a single printer. This will allow for greater understanding of the FDM process by deducing the interdependencies of the manufacturing parameters and the manner in which they affect properties of manufactured parts.

The tests undertaken and presented within this paper only consider their tensile properties. It is therefore necessary to undertake further testing to ascertain whether the findings in this paper remain true for other mechanical properties such as flexion and compression.

\section{Conclusions}

This paper has proposed the incorporation of capability profiles into the design process for FDM as a means of facilitating agile project development. Information surrounding the gaps in existing knowledge of the FDM process has been identified. Subsequent experimental work is undertaken to determine the variability in the process and also the effects of shape and scale on the tensile properties of specimens. The results of these demonstrated variability in tensile strength of up to $26 \%$ in identical specimens. Nonlinearity is observed with respect to tensile strength as the parts are scaled with variation of up to $38 \%$. Changing ratios of infill to solid shell are identified as a cause for this. Variations in mechanical performance of up to $9 \%$ are also observed by changes in cross sectional shape. The findings of these tests were brought together to define the parameters that would need to be considered within an FDM capability profile as: layer height, build orientation, raster angle, raster width, infill pattern, infill percentage, top/bottom layers, solid shells, extrusion temperature, material type, variability \& geometry. A manner in which these could be incorporated is also proposed with the parameters grouped according to whether they directly impact mechanical properties such as UTS, the sliced geometry, or both.

\section{Acknowledgements}

The work reported in this paper has been undertaken as part of the ProtoTwin project (Improving the product development process through integrated revision control and twinning of digital-physical models during prototyping). The work was conducted at the University of Bristol in the Design and Manufacturing Futures Lab (http://www.dmf-lab.co.uk) and is funded by the Engineering and Physical Sciences Research Council (EPSRC), Grant reference EP/R032696/1. 


\section{References}

Alafaghani, A. et al. (2017) 'Experimental optimization of fused deposition modelling processing parameters: a design-for-manufacturing approach', Procedia Manufacturing, Vol. 10, pp.791-803, Elsevier B.V., doi: 10.1016/j.promfg.2017.07.079.

Amazon (2017) Mechanical Turk [online] https://www.mturk.com/mturk/findhits?match=false (accessed 6 December 2017).

ASTM (2016) Standard Test Method for Compressive Properties of Rigid Cellular Plastics 1, ASTM Book of Standards, pp.4-8, doi: 10.1520/D1621-16.2.

ASTM International (2003) Standard Test Method for Tensile Properties of Plastics, Vol. 8, pp.46-58, ASTM International, doi: 10.1520/D0638-14.1.

ASTM-D790-17 (2017) Standard Test Methods for Flexural Properties of Unreinforced and Reinforced Plastics and Electrical Insulating Materials 1, Designation: D, pp. 1-12, ASTM International, doi: 10.1520/D0790-17.2.

Attaran, M. (2017) 'The rise of 3-D printing: the advantages of additive manufacturing over traditional manufacturing', Business Horizons, Vol. 60, No. 5, pp.677-688, Kelley School of Business, Indiana University, doi: 10.1016/j.bushor.2017.05.011.

Autodesk Inc (2018) Generative Design [online] https://www.autodesk.com/solutions/generativedesign (accessed 11 December 2018).

Bächer, M. et al. (2014) 'Spin-it: optimizing moment of inertia for spinnable objects', ACM Trans. Graph., Vol. 33, No. 4, pp.96:1-96:10, doi: 10.1145/2601097.2601157.

Bartarya, G. and Choudhury, S.K. (2012) 'State of the art in hard turning', International Journal of Machine Tools and Manufacture, Vol. 53, No. 1, pp.1-14, Elsevier, doi: 10.1016/ j.ijmachtools.2011.08.019.

Casavola, C. et al. (2016) 'Orthotropic mechanical properties of fused deposition modelling parts described by classical laminate theory', Materials and Design, Vol. 90, pp.453-458, Elsevier Ltd, doi: 10.1016/j.matdes.2015.11.009.

Croccolo, D., de Agostinis, M. and Olmi, G. (2013) 'Experimental characterization and analytical modelling of the mechanical behaviour of fused deposition processed parts made of ABS-M30', Computational Materials Science, Vol. 79, pp.506-518, Elsevier B.V., doi: 10.1016/j.commatsci.2013.06.041.

ElMaraghy, H.A. (1993) 'Evolution and future perspectives of CAPP', CIRP Annals Manufacturing Technology, Vol. 42, No. 2, pp.739-751, doi: 10.1016/S0007-8506(07) 62537-2.

Fleischmann, K. (2015) 'The democratisation of design and design learning: how do we educate the next-generation designer', International Journal of Arts and Sciences, Vol. 8, No. 6, pp.101-108.

Garrett, B. (2014) '3D printing: new economic paradigms and strategic shifts', Global Policy, Vol. 5, No. 1, pp.70-75, doi: 10.1111/1758-5899.12119.

Gebler, M., Uiterkamp, A.J.M.S. and Visser, C. (2014) 'A global sustainability perspective on 3D printing technologies', Energy Policy, Vol. 74, No. C, pp.158-167, Elsevier, doi: 10.1016/ j.enpol.2014.08.033.

Gopsill, J.A. and Hicks, B.J. (2016) 'Deriving infill design of fused deposition modelled parts from predicted stress profiles', Proceedings of the ASME Design Engineering Technical Conference, Vol. 2A-2016, pp.1-10, doi: 10.1115/DETC2016-59935.

Goudswaard, M., Hicks, B. and Nassehi, A. (2018) 'Democratising the design of 3D printed functional components through a hybrid virtual-physical design methodology', Procedia CIRP, Vol. 78, pp.394-399, Elsevier B.V., doi: 10.1016/j.procir.2018.08.317.

Holst, A. (2018) Worldwide Most Used 3D Printing Technologies, As of July 2018, Statista [online] https://www.statista.com/statistics/756690/worldwide-most-used-3d-printingtechnologies/ (accessed 2 July 2019). 
Klocke, F., Brinksmeier, E. and Weinert, K. (2005) 'Capability profile of hard cutting and grinding processes', CIRP Annals - Manufacturing Technology, Vol. 54, No. 2, pp.22-45, doi: 10.1016/S0007-8506(07)60018-3.

Lanzotti, A. et al. (2015) 'The impact of process parameters on mechanical properties of parts fabricated in PLA with an open-source 3-D printer', Rapid Prototyping Journal, Edited by D. Eujin Pei, Vol. 21, No. 5, pp.604-617, Emerald Group Publishing Limited, doi: 10.1108/ RPJ-09-2014-0135.

MakerBot (2019) MakerBot Thingiverse [online] https://www.thingiverse.com/ (accessed 10 July 2019).

Newman, S.T. and Nassehi, A. (2007) 'Universal manufacturing platform for CNC machining', CIRP Annals, Vol. 56, No. 1, pp.459-462, doi: 10.1016/j.cirp.2007.05.110.

Newman, S.T. and Nassehi, A. (2009) 'Machine tool capability profile for intelligent process planning', CIRP Annals - Manufacturing Technology, Vol. 58, No. 1, pp.421-424, doi: $10.1016 /$ j.cirp.2009.03.031.

Onwubolu, G.C. and Rayegani, F. (2014) 'Characterization and optimization of mechanical properties of ABS parts manufactured by the fused deposition modelling process', International Journal of Manufacturing Engineering, pp.1-13, doi: 10.1155/2014/598531.

Pətrəucean, V. et al. (2015) 'State of research in automatic as-built modelling', Advanced Engineering Informatics, Vol. 29, No. 2, pp.162-171, doi: 10.1016/j.aei.2015.01.001.

Popescu, D. et al. (2018) 'FDM process parameters influence over the mechanical properties of polymer specimens: a review', Polymer Testing, April, Vol. 69, pp.157-166, doi: 10.1016/ j.polymertesting.2018.05.020.

Prévost, R. et al. (2013) 'Make it stand: balancing shapes for 3D fabrication', ACM Trans. Graph., Vol. 32, No. 4, pp.81:1-81:10, doi: 10.1145/2461912.2461957.

Rebaioli, L. and Fassi, I. (2017) 'A review on benchmark artifacts for evaluating the geometrical performance of additive manufacturing processes', International Journal of Advanced Manufacturing Technology, Vol. 93, Nos. 5-8, pp.2571-2598, doi: 10.1007/s00170-0170570-0.

Shapiro, S.S. and Wilk, M.B. (1965) 'An analysis of variance test for normality (complete samples)', Biometrika, Vol. 52, Nos. 3-4, p.591, doi: 10.2307/2333709.

Sood, A.K., Ohdar, R.K. and Mahapatra, S.S. (2010) 'Parametric appraisal of mechanical property of fused deposition modelling processed parts', Materials and Design, Vol. 31, No. 1, pp.287-295, Elsevier Ltd, doi: 10.1016/j.matdes.2009.06.016.

Sun, Q. et al. (2008) 'Effect of processing conditions on the bonding quality of FDM polymer filaments', Rapid Prototyping Journal, Vol. 14, No. 2, pp.72-80, doi: 10.1108/ 13552540810862028.

Tymrak, B.M., Kreiger, M. and Pearce, J.M. (2014) 'Mechanical properties of components fabricated with open-source 3-D printers under realistic environmental conditions', Materials and Design, Vol. 58, pp.242-246, Elsevier Ltd, doi: 10.1016/j.matdes.2014.02.038.

Vichare, P. et al. (2015) 'Machine tool capability profiles for representing machine tool health', Robotics and Computer-Integrated Manufacturing, Vol. 34, pp.70-78, Elsevier, doi: 10.1016/ j.rcim.2014.11.002.

Wittbrodt, B. and Pearce, J.M. (2015) 'The effects of PLA color on material properties of 3-D printed components', Additive Manufacturing, Vol. 8, pp.110-116, Elsevier B.V., doi: 10.1016/j.addma.2015.09.006.

Wittbrodt, B.T. et al. (2013) 'Life-cycle economic analysis of distributed manufacturing with open-source 3-D printers', Mechatronics, Vol. 23, No. 6, pp.713-726, Elsevier Ltd, doi: 10.1016/j.mechatronics.2013.06.002. 